\title{
Political Entrepreneurs, Indeterminate Goods and the Dynamic of Green Markets
}

\author{
Louis Jaeck $^{1,2}$, Gilbert Bougi ${ }^{2} \&$ Audrey Buf ${ }^{2}$ \\ ${ }^{1}$ Department of Economics and Finance, College of Business and Economics, United Arab Emirates University, \\ UAE \\ ${ }^{2}$ Faculty of Economics and Business, Cergam-Cae, Aix-Marseille University, France \\ Correspondence: Louis Jaeck, Faculty of Economics and Business, Cergam-Cae, Aix-Marseille University, \\ France. E-mail: Louis_jaeck@hotmail.com
}

Received: May 25, 2012

Accepted: June 7, 2012

Online Published: December 31, 2012

doi:10.5539/ibr.v6n2p77

URL: http://dx.doi.org/10.5539/ibr.v6n2p77

\begin{abstract}
This paper sheds new lights on the green consumption phenomenon, and more generally on the determinants of the dynamic of green markets. We argue that some green goods such as carbon labeling products are indeterminate goods (Lupton, 2005). Using Kuran and Sunstein (1999)'s analysis that extends Lupton's framework, we develop the idea that the dynamic of indeterminate markets depends on a random selection process within which political entrepreneurs may use strategically collective beliefs about product characteristics. Our innovative framework, which is based on the impact of socially constructed information and that of social sanctions, gives challenging insights to study green consumerism.
\end{abstract}

Keywords: green consumption, beliefs, political entrepreneurs, indeterminate goods

\section{Introduction}

The emergence of green markets is a result of a spontaneous evolution of producers and consumers' behaviours towards environment-friendly choices. Green products are differentiated from standard products by allegations that inform consumers about their environmental characteristics. Today, green markets are expanding in many sectors of the economy in response to a willingness-to-pay premium for goods and services with environmental benefits. According to the categories of goods developed by theorists of economics of information (Nelson, 1970; Darby \& Karni, 1973), most environmental attributes such as recyclable or biodegradable features of the product or the environment-friendly nature of production processes belong to the category of credence goods. The quality is unknowable for the consumer before and even after consuming the product. Search information costs are prohibitive, so that the consumer has to believe the information conveyed by the environmental allegation if he wants to evaluate the quality of the product and express his green preferences through the purchase of the product. Nevertheless, green markets may be exposed to consumer confusion due to the multiplicity of information concerning other characteristics of the product and also to the well-known adverse selection phenomenon. Mechanisms such as the signalling of quality through quality labels, minimal quality standards have been implemented in order to restore the efficiency of the transaction and remedy these phenomena. Most importantly, eco-labels have been developed extensively (Note 1). They give information concerning environmental characteristics of the products. In order to generate a change in buyer behaviour, this information must be based on reputation or spread a credible signal. Producers can achieve this goal by certifying environmental characteristics of their products by a third credible party (Note 2). To convert consumers' environmental consciousness into purchase decision, eco-labels must catch consumers' attention that possesses limited cognitive abilities. Therefore, they should be credible and comprehensible (Note 3). In this case, they change credence environmental attributes into search attributes and reduce evaluating and comparing costs of consumers who face an information overload. In this way, eco-labels allow consumers to discriminate between high and low environmental quality products, reinforce their trust towards green products and reduce the adverse selection risk (Note 4). Undoubtedly, there are some empirical evidences showing the interest of consumers towards eco-labeled products. Indeed, the German Blue Angel label has been credited for a reduction in emissions of sulphur dioxide, carbon monoxide by more than 30 percent. In Sweden, the Good Environmental Choice and the Nordic Swan labels have been credited for a considerable reduction in chlorinated compounds, acids, and other pollutants from the Swedish Forest Industry 
(Thogersen, 2002). In that country, laundry detergents represent 70 percent of the annual consumption of household chemicals. Since the Good Environmental Choice and the Nordic Swan labels were introduced in the late 1980s, Swedish consumers have rejected the most environmentally harmful chemicals. In addition, eco-labeled detergent had a market share of more than 90 percent in Sweden during the year 1997 (Note 5). It is undeniable that the diffusion of green products is widely observed. This paper seeks to deeper our understanding of the phenomenon of green consumption, and we focus particularly on the impact of the socially constructed information on consumers behaviours. We first give an overview of the main contributions of the literature on green consumption. We particularly focus on models of moral motivations (section 2). In the third section, we present Lupton (2005)'s contribution that introduces a new category of goods, namely, indeterminate goods, and that sheds new lights on the dynamic of indeterminate markets. We further show that carbon labelling product may belong to that category (section 3). The fourth section will be devoted to a thorough extension of Lupton's framework. Especially, we deeper the relationship that exists between political entrepreneurs, beliefs formation process and regulations associated with indeterminate markets (section 4). The fifth section applies the Lupton's extended framework to study the dynamic of green markets. We specifically focus on carbon labelling products and develop the idea that markets dynamic depends on a random selection process within which political entrepreneurs play an important role. Our innovative framework, based on the impact of socially constructed information and that of social sanctions, brings new insights to deal with green consumerism (section 5). Section six gives some concluding remarks (section 6).

\section{The Green Consumption Phenomenon: Issues and Debates}

The analysis of environment-friendly product consumption poses a problem to economists because the benefits of private consumption have a collective dimension. As the environment is a collective good, consumers will understand that their private consumption will have a very low impact on the improvement of environmental quality because the latter is the result of a collective consumption. Consequently, they would be willing to pay a higher price for green products if one gives them the assurance that other consumers would behave similarly (Note 6). Nevertheless, even if they possess that knowledge, they could rationally demonstrate free-riding behaviours (Andreoni, 1988). In order to explain those consumption patterns where the free-riding phenomenon should make them theoretically improbable, the literature has suggested several explanations.

First, green consumerism is coherent with economic models that integrate moral motivations into consumption behaviours. In that kind of models, contributing to the public goods also produces some kind of private benefit to the contributor. Specifically, it assumes that people achieve a "warm glow" by contributing to public goods (Andreoni, 1990; Hollander, 1990). Moral motivation models explain deeply why people would contribute to the public goods. One model developed by Brekke and Rege (2003) assumes, for instance, that individuals have preferences for achieving and maintaining a self image as a socially responsible person. Self image improves when an individual's actual behavior gets closer to his view of the "morally ideal" behavior. The latter is defined as that behavior which, according to the individual's own judgment, would maximize social welfare if chosen by every member of society. Applying this reasoning to green consumption means that the individual increases his self image when he consumes a green product. Let us note, however, that the individual must be previously aware of environmental issues before consuming the product. Moral decision-making has long been studied by social psychologists. One important contribution is the work of Schwartz (1970) who has developed a social-psychological model of altruistic behavior. The problem is to understand the process by which altruistic social norms translate into individual behavior. According to Schwartz, the process begins with social norms regarding moral behavior which people generally agree upon. These norms represent the values and attitudes of significant others; we expect others to act in the morally proper way, and they in turn expect the same of us. The social norms are adopted by each of us on a personal level and thus become personal norms. To violate a personal norm generates guilt, and to uphold a personal norm generates pride. Nevertheless, individuals may internalize the norms and still not act in accordance with them. Schwartz thus identifies two variables that influence whether or not personal norms translate into behavior: the awareness of the consequence that action or inaction will have, and the ascription of responsibility for those consequences. When these two variables are high, personal norms translate into behavior (Note 7).

Second, models of social sanctions may have some explanatory power to green consumerism. For instance, Rege (2004) shows that when contributions to public goods are motivated by the desire for social approval from others, multiple equilibria may result, including one case in which no-one contributes and a second case in which everyone contributes. These outcomes are distinguished by the extent to which social norms for contributing to collective goods are recognized and enforced. Nevertheless, to our knowledge, there are not any applications of these models to the issue of adoption and diffusion of green products. According to Howarth, Nyborg and Brekke 
(2006), models of social sanctions would be limited to explain green consumerism. Indeed, empirical studies have found evidence that psychological forces such as internalized moral motives, may also be at work. In a survey conducted in Norway, for example, Bruvoll, Halvorsen and Nyborg (2002) found that while $41 \%$ of those who engaged in recycling agreed with the statement "I recycle partly because I want others to think of me as a responsible person," as many as $73 \%$ agreed that "I recycle partly because I want to think of myself as a responsible person." Howarth et al. (2006) underlines that such models are often based on highly simplified assumptions regarding the psychological considerations that motivate people to undertake other-regarding actions. Also, these models typically produce unique equilibria and neglect the cognitive aspects of a decision motivated by moral considerations. These authors refer to Schwartz's (1970) argument while integrating these cognitive aspects into their analysis. They develop the idea that herd behavior toward green products is observable when consumption is motivated by internalized social norms. In a simplified model where agents can choose between a "green" product and "brown" one, they assume the following assumptions: First, that people get an improved self-image from purchasing "green" rather than "brown" products. This self-image benefit is increasing in the individual's beliefs about the external benefits of choosing green. For instance, the success of the dolphin safe label may be attributed to a video that depicted the dramatic effects on dolphins of traditional tuna harvesting. Second, the self-image benefit is increasing in the personal responsibility the consumer feels for the issue. Perceived responsibility is, in turn, larger the more common it is to choose the green alternative. High adoption rates thus influence consumers' propensity to interpret product adoption as a matter of moral responsibility. One may describe the consumer's behavior as follow: "I know that others consume the green product, thus, I feel responsible if I consume it as well". What is worth mentioning is that their model suggest that advertising campaigns that promote the belief that "green" products provide important environmental benefits could increase the share of green consumers. In the same way, advertising campaign may influence consumers' perceptions of the share of others who purchase green products (Note 8). In this respect, they note that advertising campaign could be consciously exploited by marketers seeking to manipulate consumer's perceptions of the product environmental attribute as well as market share to increase the rents derived from producing "green" products. The strength of their model is to highlight many pro-environmental behaviors that are unobservable such as recycling. Indeed, to some extent, models of social sanctions fail to explain these behaviors.

All of these models have some explanatory power to the phenomenon of green consumption. They are particularly useful to deal with the expansion of green products that have experience and credence characteristic. And yet, in the field of economics of quality, a new category of goods has emerged in the literature, namely, indeterminate goods (Lupton, 2005). At present, our goal is to show that some green goods such carbon labeling product may belong to that category. We then raise the question of the determinants of the diffusion of these goods, and to achieve this end, we develop a challenging framework that integrates cognitive aspects as well as the impacts of social sanctions to deal with imitative behavior. We will thus suggest a complementary analysis to that of Howarth et al. (2006).

\section{Green Goods as Indeterminate Goods}

In a challenging contribution, Lupton (2005) focus on economic problems associated with products quality uncertainty. Economic problems linked to this quality uncertainty have been extensively analyzed, notably in major contributions from Arrow (1963) or Akerlof (1970). However, quality uncertainty has essentially been considered as a lack in the consumer's knowledge, of which the omniscient producer takes advantage. Lupton gives a new vision on the nature and status of quality uncertainty. She argues that uncertainty about a product's quality can be shared by all agents in the market (buyers, sellers, etc...), and this uncertainty can disrupt the market. This shared uncertainty finds its true meaning with the complexity of the production goods and services, composed of many different substances and subject to many intermediary agents. In this respect, no agent can really assume he perfectly knows the product. Recognizing the existence of this "shared uncertainty" opens new perspectives to deal with the determinants of the markets dynamic. As far as the product quality is concerned, she is interested in three types of product uncertainties: uncertainty due to the actual making of the product, uncertainty due to the past of the product and uncertainty due to future impacts of the product. We focus here on the third type of uncertainty and present Lupton's argument who deals with a specific aspect of quality, namely product safety.

Much works have been done showing that markets are confronted by difficulties due to controversies over product safety. The literature mainly focuses on problems of asymmetric information, and mechanisms to reduce ignorance and protect consumers (Daughety \& Reinganum, 1995; Goldberg, 1974). Some authors deal with the scientific uncertainty regarding the health impacts of food products (Phillips \& Isaac, 1998; Henson \& Caswell, 1999), but when they analyze quality uncertainty, characteristics are either considered as experience or credence characteristics. However, scientific controversies concerning GMOs, hormone-treated beef or the spreading of 
sewage sludge show that markets dynamic depends on the product indeterminacy regarding impacts on health and the environment. Potentially dangerous substances are identified, but the scientific knowledge with regards to their effects is shared by producers, consumers and all agents linked to the market. The idea is that some groups of agents may develop different contrary judgments about the product impacts. They may strategically use scientific expertise to reject a product but they can also ban a product because of lack of scientific knowledge (Note 9). To deal with the issue of fragility and the dynamics of these markets, Lupton gives the basis of an innovative framework by introducing a new class of goods that adds to the former classification of experience, search and credence goods. These goods are named "indeterminate goods". The latter is defined as goods or services whose characteristics cannot be known either before purchase, or once they are consumed (experience good), or again through additional costly information (credence goods). In the field of product safety, this indeterminacy refers to the product impact on health and the environment. Indeterminate goods are very different from experience and credence goods regarding the definition of quality and the nature of uncertainty, the cost of acquiring information and the nature of market problems. First of all, the notion that shared uncertainty must be distinguished to that of asymmetric information. In a context of asymmetric information, uncertainty about product quality is defined as consumers' lack of information about the product's characteristics. But the characteristics of the good are clearly defined and known by the producer. Conversely, in a context of shared uncertainty, all the agents linked to the market are ignorant about the indeterminate characteristic of the product. Here, uncertainty about the good's characteristics cannot be controlled. It might be magnified or minimized to justify the different actions and expertise of agents. Different causal interpretations coexist, without any one version proving to be the right and unique answer. It can be defined as a radical uncertainty in the sense or a perceived uncertainty.

In addition, the costs of acquiring further knowledge of quality are very different. For experience and search goods, costs are linked to acquiring existing information that is already available and known to the producer. For indeterminate goods, these costs cannot be evaluated ex ante, as they consist in spending resources to create knowledge in order to bring evidence concerning the future impact of the product. This can be acquired through research investments for instance. Consequently, the cost of acquiring information is much higher for indeterminate goods than for credence goods.

Finally, the dynamics of markets of credence goods are subject to Akerlof's (1970) mechanism, according to which there may be no demand at all, as consumers cannot distinguish between a good and bad quality car, and they anticipate that the average quality will always be inferior to the expected quality. In the end, the market actually does provide more and more poor quality products. But in the case of indeterminate goods, the market can collapse because some influential groups use strategically the shared uncertainty about the product characteristic. These groups seek to influence public opinion on the health and environmental impacts of the products in order to generate standard or some kind of product ban. According to Lupton (2005), consumers adopt Keynesian mimetic behavior. Indeed, as they think the rest of the world is better informed, they will not act according to their own opinion of the quality of the product but according to the average opinion of the market, so that the outcome is a conventional judgment on the quality of the product. The market collapses because of the changing general opinion on the quality of the product, without any change as to the intrinsic quality of the product. The case of the ban of the spreading of sewage sludge illustrates the underlying mechanism of the dynamic of these markets.

By introducing a new class of goods, the Lupton's theoretical innovation is interesting because it opens new perspectives to study green consumption phenomenon and the dynamic of green market in general. Indeed, we have previously noticed that most of green goods belong to the category of experience or credence goods. And yet, green goods such as "carbon" labeling product may be defined as indeterminate goods. Concern about climate change has stimulated interest in estimating the total amount of greenhouse gases (GHGs) emitted during the production, processing, retailing and use of many consumer goods (Smith et al., 2005). The outcome of these calculations is the carbon footprint, which reports the total amount of GHGs produced for a given activity. Since the middle of the two thousand years, carbon labels that signal a summary of the carbon footprint of a product to consumers have emerged significantly. They have been particularly developed in the UK and have targeted primarily food products (Note 10). Although carbon footprints have been used by businesses in order to inform their internal environmental management, carbon labels which inform consumers about the carbon content of a product, allow them to contribute to the GHGs emission reduction through their purchase behavior. We argue that the environmental impact of such carbon labeling products is indeterminate for mainly two reasons. First, research around academic literature has revealed that carbon footprinting generally lacks transparency in its meaning and methods of calculation (Wiedmann, Barrett \& Lenzen, 2007). Besides, the study of Gadema and Oglethorpe (2011) conducted in the UK showed that when asked specifically whether they would find advantage in having 
carbon labels, $81 \%$ of respondents strongly agreed that understanding carbon footprint information and comparing carbon footprints were difficult and confusing. Second, although climate policies are widely implemented throughout the world, climate science is a complex science within which there are scientific controversies as to the causal relationship between human GHGs emissions and climate change (Jaeck, 2011). Consequently, if we follow the logic developed by Lupton (2005), the indeterminate characteristic of carbon labeled products, namely their uncertain impact on tackling climate change, could be strategically used by actors linked to the market. On the basis of Lupton' ideas, we seek to analyze the dynamic of these markets; however, we will propose a more refined conceptual framework. Indeed, she neglects the impact of the social construction of information and particularly the mechanism by which collective beliefs about products indeterminate characteristics develop throughout the society. We now turn to some criticism and extension of Lupton's work. This extension will provide the theoretical basis of our framework.

\section{Indeterminate Goods, Beliefs Formation Process and Regulation}

The issue of what determine the collapse of indeterminate markets is only partially analyzed in Lupton's work. She argues that consumers adopt mimetic behavior and will not act according to their own opinion of the quality of the product but according to the average opinion of the market. The idea that consumers are rationally ignorant about the product characteristic is present, nevertheless, the link between such incomplete information and the development of collective beliefs about the product quality is absent from the analysis. In this respect, Kuran and Sunstein (1999)'s work that focus on the determinants of risk regulation, take into account that relationship. Indeed, they advocate that activists might influence public decision makers by using biases in risk perception (Note 11). For them, risks regulation related to human health or the environment might be disconnected from real risks and generates a waste of resources. They insist on the fact that new forms of collective actions might strategically use risk perception biases and individual mental shortcuts in order to affect individual judgements about risk issues. The issue of risk perception has been widely analyzed by cognitive psychologists. Most of these works concern laboratory experiments that show problems in treating information, leading individuals to biased risks perception (Note 12). Nevertheless, Kuran and Sunstein (1999) argue that these works are based on laboratory experiments and thus neglect the role of interdependence among individuals. More specifically, such works neglect the role of social dimension of information acquisition. Yet, the key point of Kuran and Sunstein's analysis is to show that the social interactions process generates incorrect collective beliefs which in turn lead to counterproductive public policy (Note 13). In their analysis, Kuran and Sunstein (1999) particularly focus on the interaction between availability heuristic and the social interactions process to explain collective belief formation. They do so by referring to concrete examples, such as the Love Canal story.

\subsection{The "Love Canal" Story}

Between 1942 and 1953, Hooker Chemical Company filled Love Canal, an abandoned waterway that flows into the Niagara River in the State of New York, with more than 21,000 tons of chemical waste. In 1957, the local government developed the area, turning it into a neighborhood. In 1976, the canal overflowed its banks after several years of heavy precipitation. In the same year, a commission responsible for monitoring the Great Lakes detected Mirex Insecticide in Lake Ontario, and the New York Department of Environmental Conservation identified Love Canal as a major source of this insecticide. Immediately, the local press reported the fear that residents had concerning the side effects of the insecticide on human health, thus developing many rumors in the area. Government officials ordered a series of tests that showed low levels of carcinogens in a basement near the dump site. In 1978, the EPA confirmed the findings and declared that the water was safe to drink and that Lake Ontario was not contaminated. In June 1978, however, Marie Gibbs, who was the president of the Love Canal Homeowners Association, played a key role in reinforcing fears of adverse health effects and mobilizing public opinion. This activist appeared on television, at the Capitol building, and organized demonstrations in the area. Responding to the outcry, New York State Health Commissioner Robert Whalen declared a public health emergency in the area in 1978. He urged area residents to stay out of their basements and avoid eating anything from their gardens. He also organized the temporary relocation of twenty-five pregnant women. In September 1978, he published a report entitled Love Canal: Public Health Time Bomb which described Love Canal as a disaster area. At the same time, Governor Hugh Carey who was at the height of his re-election campaign followed Whalen's vision. He promised state aid for the locality and granted the relocation of 239 families living closest to the canal, all at the state's expense. From the standpoint of the federal government, President Carter declared an emergency in the area. Few days after his declaration, scientists re-examined the facts and showed that the health risks had been overestimated. Nevertheless, this event was covered by the media, in particular the New York Times. In May, President Carter ordered the relocation of 700 additional families which cost three million dollars. 
The same year, Congress established the Superfund program (Note 14).

\subsection{Social Construction of Information and Irrational Public Policies}

For Kuran and Sunstein (1999), the Superfund program was the result of the highly publicized Love Canal story. Also, opinion polls had revealed that $80 \%$ of U.S. citizens supported state intervention to treat this environmental problem (Note 15). As the authors underlined it, the emergence of such collective fear about risks which do not reach a scientific consensus is a phenomenon in accordance with an essential result of cognitive psychology, namely, the limited rationality of individuals (Note 16). Due to limited cognitive abilities, individuals rely on heuristics in order to develop their own judgment about risks. This attitude might lead to erroneous judgments. Kuran and Sunstein (1999) insist on the fact that media coverage and different meetings prove that interdependence between individuals explains the emergence of such collective fears. The latter are the result of the influence of new forms of collective actions. This argument is based on two hypotheses concerning individual behaviour.

First, individual's cognitive abilities are limited. Consequently, in order to form their personal risk judgment, they rely on availability heuristics. Second, individuals are looking for social approval. Their personal judgments about risks are related to rational behaviour seeking to maintain their reputation. In both cases, their behaviour is in accordance with the rational choice model. More precisely, Kuran and Sunstein (1999) have argued that collective beliefs formation about risks is the result of a circular process between risks judgment expressed publicly and the formation of personal risk judgment. Thus, information about risk is socially constructed and influences the collective beliefs formation. This process originates from the behaviour of activists that might also be named political entrepreneur, who launch the formation of such beliefs. The latter develop throughout two mechanisms that are in interaction. First, they may develop due to an informational cascades mechanism. Second, they form throughout a reputational cascades mechanism (Note 17).

\subsubsection{Mechanism of Collective Beliefs Formation Process}

Several theories have been suggested to explain uniformity in social behavior. For instance, Akerlof (1980) and Kuran (1989) showed that reputational effects and social sanctions may generate uniform behavior among the public. Jones (1984) simply claimed that the main motivation for individuals conforming to their peers is imitation. Such theories explain how constraints and circumstances affect uniformity and rigidity of social behaviors. Nevertheless, theoreticians of information cascades such as Bikchandani Hirshleifer and Welch (1992) or Hirshleifer (1995), argued that it does not explain why uniform behavior would lead to errors and why mass behavior is fragile and subject to evolution. The basic idea is that an informational cascade emerges when it is optimal for an individual to rely on the observation of the behaviour of others and neglect his private information when he has to decide an action. The singularity of this theory is that these imitation phenomenon are based on the rational behaviour of individuals in a context of incomplete information. Looking at the Welsh (1992)'s example about a choice of restaurant, Bonardi and Keim (2005) describes the information cascades mechanism as follow. The first step is that a set of individuals makes a similar decision in sequence - for instance, whether or not to eat at a specific restaurant along a busy tourist avenue. None of the individuals knows for certain what benefits he will derive from such a decision. Each has a probability of liking the restaurant choice, based on information he receives prior to the decision. When the first customer makes a decision, his only source of information is the prior information received. After the first actor chooses, however, there is additional information available to those who have yet to choose - the sight of the first actor going into or eating at the restaurant. The second individual observes what the first one did, which impacts her probability of choosing, and then he makes her decision. If the signal he gets from the prior individual's actions offsets the information from the signal prior to the game, then he flips a coin to make the decision. At the time the third individual makes a decision, his own private signal may be outweighed by the information he receives from observing the first two choosers, and he may decide to go to the restaurant, regardless of her original signal. A fortiori, the next individuals will all do the same, and an up information cascade has been generated.

Informational cascades theory diverges from other theories of conformity of behaviour by focusing on the fact that mass behaviour develops rapidly and is fragile. In the sequence, the credibility of the first and second individual is crucial to affect the choice of the third one. Indeed, social psychologists report that people imitate the actions of those who seem to have expertise in a field. According to Bikchandani et al. (1998), this explains the success of product endorsements in which athletes are seen to use a particular brand of athletic shoes. To start a cascade, the first individual must be an expert or a "fashion leader". Nevertheless, cascades are fragile; several kinds of shock could reverse a cascade such as the release of new public information or the arrival of a better informed individual such as an expert. Also, the main problem with such informational cascades is that they may be erroneous. Indeed, 
even if the information precision of the first individual is high, it is not obviously better than the combination of different private information of later individuals.

According to Kuran and Sunstein (1999), the information cascade mechanism explains the formation of individual judgments on risk issues as well as erroneous collective beliefs. Indeed, the "Love Canal" case is in keeping with the predictions of information cascades model. On the one hand, it is costly to have access to information on risk issues because such scientific information is complex and belong to the scientific community. Consequently, the quality of the private information possessed by individuals is very low. Individuals thus use the availability heuristic and develop their own judgments by observing the judgments of others. On the other hand, political entrepreneur such as Marie Gibbs contribute to start information cascades through their public discourse in the media (Note 18). They are perceived by the public as leaders with a high quality of private information on risk issues. Also, the alarmist publication of Mr. Whalen, the aforementioned health commissioner, has contributed to reinforce the cascade. Finally, it seems that the collective beliefs were erroneous if one considers the persistent doubt among the scientific community. Such a result is in line with the predictions of information cascades theory. Indeed, it predicts that the probability of convergence towards erroneous behavior is high. This result holds especially in the case where the private information is non observable for individuals, which prevents the information aggregation process and the correction of errors.

Nevertheless, for Kuran and Sunstein (1999), the collective beliefs formation also results from a reputation cascades mechanism. The latter has its roots in Kuran (1990)'s work about the preference falsification process. Revealed preference theory suggests that preferences of individuals may be deduced from the observation of their action. Nevertheless, Kuran (1990) argued an individual who joins a riot against a government does not necessarily support a change in the political regime. It might be costly for him if he does not participate. According to Kuran (1990), there are contexts where individuals can be punished or rewarded according to the preferences they express through their actions. In public choice analysis, this theory may lead to misinterpretations. In his article, Kuran (1990) develops a framework which seeks to study individual choices including a study of a wide range of motivations. More precisely, individual utility has three dimensions: the social choice, social sanctions associated with individual choice, and the autonomy of individual decision. These three conflicting factors of utility generate, for each individual, a private preference and a public preference, the latter being the one he reveals to others through his actions. The divergence between these two types of preferences is at the heart of his preference falsification theory. According to Kuran (1990), his theory provides a better understanding of individual behaviour than traditional theory because an individual derives satisfaction from different conflicting sources. This framework explains several social and economic choices where reputation is a part of utility (Note 19), and combining with the existence of informational cascades, it gives a thorough understanding of how erroneous collective beliefs develop and spread in the society.

\subsubsection{The Interaction between Informational and Reputation Cascades}

According to Kuran and Sunstein (1999), the preference falsification phenomenon contributes to the emergence of irrational policies to manage risks. It has been discussed that an erroneous collective belief may develop due to the information cascades process. Such erroneous collective belief may in turn lead the opportunistic politician who wants to maintain his popularity, to falsify his preference and implement policies disconnected from real risks. If one considers the Love Canal story, the attitude of Governor Hugh Carey as well as that of President Carter might be related to preference falsification since the scientific community had demonstrated that risks were overestimated. Such behaviors of policymakers contribute to reinforce the erroneous collective belief among the public and prevent it from being reversed. As soon as the collective belief has reached a critical size, it affects the reputation benefits and costs of individuals who have not yet adopted the beliefs, and incites them to falsify their preferences (Note 20). The collective belief may therefore expand through a reputation cascade mechanism (Note 21). This phenomenon leads to a falsification of knowledge, which, combined with the loss of knowledge generated by the information cascade, reinforces the probability of expansion of an erroneous collective belief (Note 22). Consequently, the collective beliefs formation on risk issues is the result of an interactive circular process between judgments that are expressed publicly and the formation of private judgments. Kuran and Sunstein (1999) thus highlight the relationship between the preference falsification process, the social construction of information, and the irrationality of public policies to manage risk issues.

Several author have referred to Kuran and Sunstein's analysis. Bonardi (2005) improves notably the relationships between political entrepreneur/activist, experts and the media that enhance the emergence and the strength of collective beliefs (Note 23). Indeed, the development of reputation cascades among the expert community is a necessary condition to avoid the reversal of information cascades initiated by political entrepreneurs (Note 24). Notably, he cites the case of the GMO importing ban within the EU that has been largely the result of the influence 
of groups such as ATTAC or Greenpeace in the media.

In our view, Kuran and Sunstein's analysis which describes the beliefs formation process and their effect on risk regulation is a considerable improvement of Lupton's work about the dynamic of indeterminate markets. Indeed, they explicitly take into account the link between political entrepreneurs, the emergence of collective beliefs and regulations. We now refer to this framework to study the dynamic of green goods that belong to the class of indeterminate products. We develop especially the idea that the dynamic of these markets resembles a random selection phenomenon.

\section{Random Selection and the Dynamic of Green Market}

As it has been mentioned previously, carbon labeling products may be defined as indeterminate goods. In that section, we argue that the process by which such green goods expand on or disappear from the market is a process that we call random selection. This process depends intrinsically on the beliefs formation process through cascades effects. We develop this argument by using the logic of Hirshleifer's model (Hirshleifer, 1995). The author is interested in the decision of smoking. We suggest a similar analysis by studying the consumption choice between "a carbon labelling product" and "standard product". The assumptions of the model are as follows: One considers a sequence of individuals who may decide to buy the green product or not to buy it. Each individual knows his position in the sequence. Each individual observes the actions of his predecessors, namely whether they have consumed the green product or not, and not their private signals. Indeed, each individual has a private information on the indeterminate characteristic of the product, that is, the ability of the product to contribute to the GHGs emission reduction (Note 25). Each individual will develop a belief concerning the product's indeterminate characteristic on the basis of its private information and the observation of the behavior of others individuals. One may present the logic of the model as follow: The first individual in the sequence observes a positive signal about the good indeterminate's characteristic and decides to consume product A (which is a carbon labelled product). The second individual does not know the signal perceived by the first individual but he deduces he has perceived a positive signal from the observation of his action. He decides to consume product $\mathrm{A}$ if his private signal is positive. If he perceives a negative signal (namely that the environmental impact of the product is low), he flips a coin to decide to consume product A. As soon as the third individual decides, the informational cascade starts. If one assumes the case where the two predecessors have consumed product A, the third will consume the product too. Indeed, the model supposes the third individual knows the signal perceived by the first individual. So he deduces from the observation of the second individual that he has perceived a positive signal. He will thus neglect his private information and will develop the belief that the environmental impact of the product is very high, and therefore he consumes product A. All the followers behave like the third one, and we observe the diffusion of the product A. In this case, an "up cascade" develops. By analogy, if the first two individuals do not consume the product, a "down cascade" will emerge and we observe the diffusion of the standard product. This reasoning calls for several remarks.

First, the action of the second individual depends on the credibility of the first one. If the first individual is an environmental expert for example, the second will attach to his behaviour much more credibility even if he does not know his private signal (Note 26). In the same way, the status or profession of the first individual reinforces the formation of the belief of the third individual even if he knows his private information. Thus, one of the strong assumptions of informational cascades theory is that individuals, which are rationally ignorant, neglect their private information and develop their belief on the ground of the observation of the behaviour of only two individuals. We believe this assumption remains realistic due to the current context characterized by complex and overloaded information concerning climate change issues.

Second, the transformation of that belief into green purchase behaviours is not certain because individuals may not buy the product due to the free ridding problem. Consequently, if we look at the particular case of the expansion of the green good, the analysis must be deepened at several levels. First of all, the first individuals in the information cascade have an incentive to free ride even if they believe that the good's environmental impact is real and effective. As the good's characteristic generates collective benefits when the good is consumed individually, it is necessary to assume that the information cascade will develop first among individuals who have strong ecological preferences when they learn about the good's environmental impact, no matter what the objective quality of the information cascade is. One may assume for instance that these first individuals in the sequence achieve "a warm glow" by consuming the product and therefore contributing to the public good. Second, in order to explain by which mechanism the green consumption might expand throughout the rest of the population, one need to take into account the effect of a critical size of green consumers on the incentives of others individuals to consume the green product. Indeed, if we follow Kuran (1991)'s reasoning who introduces the impact of social sanctions into the analysis of human behavior, a critical size of individual should exist in the society to affect reputation costs and 
benefits associated with a particular behavior or opinion. In our example, a critical size is achieved when early consumers with "warm glow" green preferences start the information cascade. Then, the more the green consumption phenomenon increases, the more individual reputation benefits of green consumption as well as individual reputation costs of the standard consumption increases. In that process, later individuals in the sequence are only sensible to sanctions and rewards associated with the different types of consumption (Note 27). However, we argue that achieving a critical size is not a sufficient condition to make social sanctions effective. Collective beliefs associated with the risk of climate change if the GHGs emissions are not tackled might play an important role. Therefore, reputation benefits and costs of later individuals in the sequence are logically affected by the consumption behavior of their peers, but also by the nature of public opinion about climate risk and how to handle it.

So far, we have provided a theoretical framework that allows us to describe the expansion of green goods with indeterminate characteristics. If we now turn to the analysis of the dynamic of such markets, namely to what extent green goods may expand on or disappear from the market, it is necessary to take into account of the fragility of information cascades. Indeed, information cascades theoreticians have shown that since the individual neglects his private information, cascades related to the environmental impacts of carbon labeling products, or those associated with climate change risk may be easily reversed if a new "fashion leader" or expert joins the sequence. If one takes into account these effects, the dynamic of indeterminate goods market depends on random selection (figure 1). This phenomenon which is implicitly described in Lupton's work seems better explicit taking into account the logic of beliefs formation trough cascades effects. Besides, such logic refers explicitly to the role played by political entrepreneurs who seek to initiate information cascades in accordance to the ideas they support. In this respect, we note that the dynamic of markets trough a random selection process allow us to introduce "traditional" entrepreneur into the analysis. Indeed, the latter may engage themselves into political entrepreneurship strategies to reach their economic goals. During the competition process between carbon labeling producers and standard producers, using strategically the information associated with environmental impacts of the product could be a new weapon to compete and win market shares (Note 28).

\section{Concluding Remarks}

This paper has shed new lights on the green consumption phenomenon, and more generally on the determinants of the dynamic of green markets. The literature has principally analyzed such dynamic through adverse selection in a context of information asymmetry. We have argued that some green goods, notably, carbon labeling products, belong to the category of indeterminate goods. The dynamic of such markets is thus better analyzed in a context of shared uncertainty, and it depends on the impact of collective beliefs related to the products' environmental impact on consumption decisions. This argument, which originally comes from Lupton's contribution, has been considerably deepened. Particularly, we have demonstrated that Kuran and Sunstein's (1999) analysis related to the beliefs formation process and its effect on regulation, is complementary to that of Lupton. Using Kuran and Sunstein (1999)'s framework and extending it to the issue of the dynamic of indeterminate good markets, we have developed the idea that markets dynamic depends on a random selection process within which political entrepreneurs initiate information cascades. Our innovative framework, based on the impact of socially constructed information and that of social sanctions, allows us to bring new insights to study green consumption. In terms of carbon labeling, according to a recent study for the EU Directorate-General for the environment 72 per cent of EU citizens support carbon labeling and think that it should be mandatory in the future (The Gallup Organization 2009). Nevertheless, according to the study of Upham, Dendler and Bleda (2011) on the perception of carbon labels by UK consumers, only a very small percentage of consumers can be expected to make use of carbon labels. Such empirical evidence may be partially explained by our approach. Indeed, the critical size of green consumers would not have been reached yet to enhance a general adoption of carbon labeling product. Looking at the factors that impact the formation of such critical size is an interesting avenue for further research. Besides, our approach is complementary to that of Howarth et al. (2006) It is clear that models of social sanctions are appropriate to study the adoption of green products for which the consumption is observable. On the contrary, Howarth et al.'s analysis is better adapted to study green consumption that is not observable. The heart of their analysis is to show that marketers may use strategically consumers' perception of the share of others who purchase green products as well as consumers' perception of the product environmental attribute. In the end, consumers interpret green products adoption as a matter of moral responsibility and are incentivized to consume the green products. And yet, we believe that the logic of the random selection process is suitable to study green consumption behaviours' that are not observable. The intrinsic mechanism underlying green consumption would not depend any more on social interdependencies between different consumers' moral motivation, but rather on the impact of collective beliefs that come from information and reputation cascade effects. In this respect, several formal 
extensions of Howart et al.'s analysis that take into account theses cascade effects are possible, and constitute promising research directions to deal with the diffusion of green products that content indeterminate characteristics such as carbon products or biofuels for instance.

\section{Acknowledgements}

We thank participants at the colloquia "Innovation, entrepreneurship and development" held at the Aix-Marseille University for their helpful comments on earlier draft of this paper. Finally we thank Anjali Nadig and Leo Wood for their helpful technical assistance.

\section{References}

Akerlof, G. (1970). The market for 'lemons': quality uncertainty and the market mechanism. Quarterly Journal of Economics, 84(3), 488-500. http://dx.doi.org/10.2307/1879431

Akerlof, G. (1980). A theory of social custom, of which unemployment may be one consequence. Quarterly Journal of Economics, 14, 749-775. http://dx.doi.org/10.2307/1885667

Allen, F. W. (1987). Towards a holistic appreciation of risk: The challenge for communicators and policy makers. Science, Technology \& Human Values, 12, 138-143.

Andreoni, J. (1988). Privately Provided Public Goods in a Large Economy: The Limits of Altruism. Journal of Public Economics, 35, 57-73. http://dx.doi.org/10.1016/0047-2727(88)90061-8

Andreoni, J. (1990). Impure altruism and donations to public goods: A theory of warm-glow giving. The Economic Journal, 100, 464-477. http://dx.doi.org/10.2307/2234133

Arrow, K. (1963). Uncertainty and the welfare economics of medical care. American Economic Review, 53(5), 941-73.

Bikhchandani, S., Hirshleifer, D., \& Welch, I. (1992). A Theory of fads fashion, custom, and cultural change as informational cascades. Journal of Political Economy, 100(5), 992-1026. http://dx.doi.org/10.1086/261849

Bikhchandani, S., Hirshleifer, D., \& Welch, I. (1998). Learning from the behaviour of others: conformity, fads and informational cascades. Journal of Economic Perspectives, 12, 151-170. http://dx.doi.org/10.1257/jep.12.3.151

Bjorner, T. B., Hansen, L. G., \& Clifford, S. (2004). Environmental labelling and consumer's choice-an empirical analysis of the effect of the Nordic Swan. Journal of Environmental Economics and Management, 47(3), 411-434. http://dx.doi.org/10.1016/j.jeem.2003.06.002

Boettke, P. (1993). Entrepreneurship. In W. Outhwaite, \& T. Bottomore (Eds.), The Blackwell Dictionary of Twentieth-Century Social Thought (p. 880). Hoboken, N.J.: Blackwell.

Bonardi, J. P., \& Keim, G. D. (2005). Corporate political strategies for widely salient issues. Academy of Management Review, 30(3), 555-576. http://dx.doi.org/10.5465/AMR.2005.17293705

Bougherara, D., Grolleau, G., \& Thiebaut, L. (2005). Can labelling policy do more harm than good? An analysis applied to environmental labelling scheme. European Journal of Law and Economics, 19(1), 5-16. http://dx.doi.org/10.1007/s10657-005-5273-6

Brady, G., Clark, J. R., \& Davis, W. (1995). The political economy of dissonance. Public Choice, 82, 37-51. http://dx.doi.org/10.1007/BF01047728

Brekke, K. A., \& Rege, M. (2003). Advertising as Manipulation of Social Learning. paper presented at the 2003 (VI) Meeting of the Society for the Advancement of Economic Theory, Rodos, Greece.

Bruvoll, A., Halvorsen, B., \& Nyborg, K. (2002). Households' recycling efforts, resources. Conservation and Recycling, 36(4), 337-354. http://dx.doi.org/10.1016/S0921-3449(02)00055-1

Caswell, J., \& Modjuszka, E. M. (1994). Using Informational Labelling to Influence the Market for Quality in Food Products. American Journal of Agricultural Economics, 78(5), 131-143.

Darby, M., \& Karni, E. (1973). Free competition and the optimal amount of fraud. Journal of Law and Economics, 16(1), 67-88. http://dx.doi.org/10.1086/466756

Daughety, A., \& Reinganum, J. (1995). Product safety: liability, RD, and signaling. American Economic Review, 85(5), 1187-206.

Davenport, T. H., \& Beck, J. C. (2001). The attention economy. Harvard Business School Press.

Enger, A., \& Lavik, R. (1995). Eco-labelling in Norway: Consumer Knowledge and attitudes. In E. Sto, \& Lysaker 
(Eds.), Sustainable Consumption-Report from International Conference on Sustainable Consumption. Nor: National Institute for Consumer Research (SIFO).

Gadema, Z., \& Oglethorpe, D. (2011). The use and usefulness of carbon labeling food: a policy perspective from a survey of UK supermarket shoppers. Food policy, 36, 815-822. http://dx.doi.org/10.1016/j.foodpol.2011.08.001

Goldberg, V. (1974). The economics of product safety and imperfect information. Bell Journal of Economics and Management Science, 5(2), 683-88. http://dx.doi.org/10.2307/3003129

Grolleau, G., Ibanez, L., \& Mzoughi, L. (2009). Too much a good thing? Why altruism can harm the environment. Ecological Economics, 68, 2145-2149. http://dx.doi.org/10.1016/j.ecolecon.2009.02.020

Henson, S., \& Caswell, J. (1999). Food safety regulation: an overview of contemporary issues. Food Policy, 24(6), 589-603. http://dx.doi.org/10.1016/S0306-9192(99)00072-X

Hirshleifer, D. (1995). The blind leading the blind. Social influences, fads and informational cascades. In T. Ierulli (Ed.), The new economics of human behaviour. Cambridge University press.

Hollander, H. (1990). A social exchange approach to voluntary cooperation. American Economic Review, 80(5), 1157-1167.

Hopper, J. R., \& Nielsen, J. M. (1991). Recycling as altruistic behavior: normative and behavioral strategies to expand participation in a community recycling program. Environment and Behavior, 23(2), 195-220. http://dx.doi.org/10.1177/0013916591232004

Howarth, R. B., Nyborg, K., \& Brekke, K. A. (2006). Green consumers and public policy: on socially contingent moral motivation. Resource and Energy Economics, 28, 351-366. http://dx.doi.org/10.1016/j.reseneeco.2006.03.001

Hung, A. A., \& Plott, C. R. (2001). Information cascades: replication and an extension to majority rule and conformity-rewarding institutions. American Economic Review, 91, 1508-1520. http://dx.doi.org/10.1257/aer.91.5.1508

Jaeck, L. (2011). Information and political failures: to what extent does rational ignorance explain irrational beliefs formation? Constitutional Political Economy, 22(3), $287-301$. http://dx.doi.org/10.1007/s10602-011-9108-x

Jaeck, L., \& Bougi, G. (2010). Dynamics of environmental regulation and voter's biased beliefs: a political economy approach. Atlantic Economic Journal, 38(4), http://dx.doi.org/10.1007/s11293-010-9243-1

Jones, S. (1984). The Economics of Conformism. Cambridge, Mass: Black-Well.

Kahneman, D., \& Tversky, A. (1974). Judgement under uncertainty: Heuristics and biases. Science, 185, 1124-1131. http://dx.doi.org/10.1126/science.185.4157.1124

Karl, H., \& Orwat, C. (1999). Economic aspects of environmental labelling. In H. Folmer, \& T. Tietenberg (Eds.), The International Yearbook of Environmental and Resource Economics. Edward Elgar: Adelshot.

Kotchen, M. J. (2005). Impure Public Goods and the Comparative Statics of Environmentally Friendly Consumption. Journal of Environmental Economics and Management, 49, 281-300. http://dx.doi.org/10.1016/j.jeem.2004.05.003

Kuran, T. (1989). Sparks and prairies fires: A theory of unanticipated political revolution. Public Choice, 61, 41-74. http://dx.doi.org/10.1007/BF00116762

Kuran, T. (1990). Private and public preferences. Economics and philosophy, 6, 1-26. http://dx.doi.org/10.1017/S026626710000064X

Kuran, T. (1991). The East European Revolution of 1989: Is it surprising that we were surprised? American Economic Review, 81, 121-125.

Kuran, T., \& Sunstein, R. C. (1999). Availability cascades and risk regulation. Standford Law Review, 51, 683-768. http://dx.doi.org/10.2307/1229439

Landesman, C. (1995). Voluntary Provision of Public Goods. (Ph.D. Dissertation). Princeton University.

Lemennicier, B. (2001). Collective beliefs formation and the politically correct concerning information on risk behaviour. Journal des Economistes et des Etudes Humaines, 11, 617-638. http://dx.doi.org/10.2202/1145-6396.1032 
Lupton, S. (2005). Shared quality uncertainty and the introduction of indeterminate goods. Cambridge Journal of Economics, 29(3), 399-421. http://dx.doi.org/10.1093/cje/bei009

Moon, W., Florkowski, W. J., Bruckner, B., \& Schonhof, I. (2002). Willingness to pay for environmental practices: implication for eco-labelling. Land Economics, 78(1), 88-102. http://dx.doi.org/10.2307/3146925

Morris, S. (2001). Political correctness. Journal of Political Economy, 109, 231-265. http://dx.doi.org/10.1086/319554

Nelson, P. (1970). Information and Consumer Behaviour. Journal of Political Economy, 78(2), 311-329. http://dx.doi.org/10.1086/259630

Noll, R., \& Krier, J. (1990). Some implications of Cognitive psychology for risk regulation. Journal of Legal Studies, 19, 749-760. http://dx.doi.org/10.1086/467870

OECD. (1997). Eco-Labelling: Actual Effects of Selected Programmes. Paris: Organization for Economic Cooperation and Development.

Page, W. H. (1999). Microsoft and the public choice critique of antitrust. Antitrust Bulletin, 44, 5-63.

Phillips, P., \& Isaac, G. (1998). GMO labeling: threat or opportunity? Agbioforum, 1(1), 25-30.

Rege, M. (2004). Social norms and private provision of public goods. Journal of Public Economic Theory, 6(1), 65-77. http://dx.doi.org/10.1111/j.1467-9779.2004.00157.x

Roe, B., Teisl, F. M., Levy, A., \& Russell, M. (2001). US consumers' willingness to pay for green electricity. Energy Policy, 29(11), 917-925. http://dx.doi.org/10.1016/S0301-4215(01)00006-4

Schmidtz, D. (1991). The Limits of Government, An Essay on the Public Goods Argument. Westview Press.

Schultz, P. W. (2002). Knowledge, information, and household recycling: examining the knowledge-deficit model of behavior change. In Dietz, T., \& Stern, P. C. (Eds.), New Tools for Environmental Protection: Education, Information, and Voluntary Measures. National Academy Press, Washington, DC.

Schwartz, S. H. (1970). Moral decision making and behavior. In Macaulay, J., \& Berkowitz, L. (Eds.), Altruism and Helping Behavior (pp. 127-141). Social Psychological Studies of Some Antecedents and Consequences, Academic Press, New York.

Simmons, T. R., Yonk, R. M., \& Diana, W. T. (2011). Bootkeggers, Baptits and political entrepreneur. The independ review, 15(3), 367-381.

Simon, H. (1982). Models of bounded rationality. Cambridge, MIT Press.

Slovic, P. (2000). The perception of risk. London, Earthscan.

Smith, A., Watkiss, P., Tweddle, G., McKinnon, A., Browne, M., Hunt, A., . . . Cross, S. (2005). The validity of food miles as an indicator of sustainable development. Final report. Defra, London.

Sunstein, C. (1998). Selective fatalism. Journal of Legal Studies, 27, 799-823. http://dx.doi.org/10.1086/468043

Sutter, D. (2002). The Democratic Efficiency Debate and Definitions of Political Equilibrium. Review of Austrian Economics, 15(2-3), 199-209. http://dx.doi.org/10.1023/A:1015766621802

Teisl, F. M., Roe, B., \& Hicks, R. L. (2002). Can eco-labels tune a market? Evidence from Dolphin Safe Labelling. Journal of Environmental Economics and Management, 43(3), 339-359. http://dx.doi.org/10.1006/jeem.2000.1186

The Gallup Organisation. (2009). Europeans'attitudes towards the issue of sustainable consumption and production. Analytical report.

Thogersen, J. (2002). Promoting green consumer behaviour with eco-labels. In T. Dietz, \& P. C. Stern, (Eds.), New Tools for Environmental Protection (pp. 83-104). National Academy Press, Washington, D.C.

Upham, P., Dendler, L., \& Bleda, M. (2011). Carbon labelling products: public perception and potential emissions reductions. Journal of Cleaner Production, 19, 348-355. http://dx.doi.org/10.1016/j.jclepro.2010.05.014

USEPA. (1993). Status Report on the use of Environmental labels. US Environmental Protection Agency, Washington DC (September).

USEPA. (1994). Determinants of Effectiveness for Environmental Certification and Labelling Programs. US Environmental Protection Agency, Washington DC (September).

Viscusi, K. W., \& Hamilton, J. T. (1999). Are risk regulators rational? Evidence from hazardous waste cleanup 
decisions. American Economic Review, 89, 1010-1027. http://dx.doi.org/10.1257/aer.89.4.1010

Welch, I. (1992). Sequential sales, learning and cascades. The Journal of Finance, 47(2), 695-732. http://dx.doi.org/10.1111/j.1540-6261.1992.tb04406.x

Welsh, H., \& Kuhling, J. (2009). Determinants of pro-environmental consumption: the role of reference groups $\begin{array}{lllll}\text { and } & \text { Eoutine } \text { Ecological }\end{array}$ http://dx.doi.org/10.1016/j.ecolecon.2009.08.009

Wiedmann, T., Barrett, J., \& Lenzen, M. (2007). Companies on the Scale: Comparing and Benchmarking the Footprints of Businesses. International Ecological Footprint Conference, Cardiff. Retrieved from http://www.isa-research.co.uk/docs/Wiedmann_et_al_2007_Cardiff_Companies_EF.pdf.

Zeckhauser, R. J., \& Viscusi, W. K. (1990). Risk within Reason. Science, 248, 559-564. http://dx.doi.org/10.1126/science.2333509

\section{Notes}

Note 1. There is a wide range of eco-labelling programs, their private or public character distinguishes them. They could be voluntary or mandatory, and they could refer to a variety of environmental attribute or a specific one. US Environmental Protection Agency (USEPA, 1993, 1994) has proposed a classification of environmental labels. Due to the increase in number of the environmental allegations sometimes without sound basis at the beginning of the eighties, ISO (International Organization for Standardization) has published norms in order to create a frame of reference in that field. http://www.iso.org/. The type 1 refers to eco-labelling programs certified by a third party. They are based on life cycle assessments, which differentiate products, by their environmental attribute. The type 2 refers to environmental claims without certification by a third party. The type 3 refers to environmental data of the product, certified by a third party. Public eco-labelling programs such as the German blue angel, the European eco-label, the Nordic Swan and the French eco-label NF environment belong to the type 1.

Note 2. Caswell and Modjuska (1996).

Note 3. For a discussion concerning the consumer attention in a context of overload information, see Davenport and Beck (2001).

Note 4. Many studies have shown the ability of environmental labels certified by a third party to create consumers trust. The reader can refer to Enger and Lavik (1995).

Note 5. One can also find empirical evidences in the work of Bjorner, Hansen and Clifford (2004), OECD (1997), Teisl, Roe and Hicks (2002), Roe, Teisl, Levy and Russel (2001), Moon, Florkowski, Bruckner and Schonholf (2002).

Note 6. Schmidtz (1991) and Landesman (1995) have highlighted this problem.

Note 7. Hopper and Nielsen (1991) have applied the Schwartz model to recycling behavior. They conduct experimental and survey data from residents of a large urban neighborhood with a communitywide curbside recycling program in order to determine the extent to which recycling could be conceptualized as altruistic behavior. Results confirmed that recycling behavior is consistent with Schwartz's altruism model, according to which behavior is influenced by social norms, personal norms, and awareness of consequences.

Note 8. Schultz (2002) quotes several studies indicating that recycling behavior is correlated with respondents' beliefs about the frequency of recycling in their community.

Note 9. The hormones dispute between the US and the EU over the hormone-treated beef trade illustrates this. In 1989, the European Commission banned the use of five hormones in meat production, claiming that hormone-treated beef is unsafe for humans. The prohibition applies to both imported and domestically produced beef. The US and Canada brought this hormone case before the WTO in February 1998 and requested a dispute settlement panel to review the ban. They questioned the scientific basis of the ban and also noted that the European measure provided a level of protection that was arbitrary and unjustified, and could therefore be considered as a disguised restriction on international trade. The EU rejected these claims. First, it argued that scientific evidence on the long-term health effects of ingesting hormone-treated beef was insufficient or non-existent. Therefore, the EU asserted that it was within its rights to exercise the precautionary principle, according to which, measures can be taken to maintain a high level of protection where scientific evidence is incomplete or unconvincing. After this defense, the US and Canada Panel Reports concluded that the EU had violated the SPS Agreement. Finally, the WTO concluded that the EU had not given sufficient scientific evidence, but the EU kept its ban, while recognizing the need to seek further information and review measures in the light of future evidence. Lupton also refer to the striking case of the ban of the spreading of sewage sludge. In France, the food industry (Panzani), mass 
marketing (Carrefour, Auchan) followed by transformers and cooperatives, started banning the spreading of sewage sludge on agricultural land from 1997 onwards, despite French legislation legitimizing this practice. These groups did not justify their refusal on scientific grounds, but based their ban on the persistent uncertainty on the health and environmental impacts of sewage sludge on lands and crops. In certain areas, this led to a massive refusal of sewage sludge by farmers, and a collapse or contraction of the spreading market.

Note 10. As Gadema and Oglethorpe (2011) have underlined, attempts to account for the interdisciplinary and overlapping nature of climate change and its inextricable linkages to food systems appears to be gaining credence as the agency, corporate and government response increasingly feature stakeholder involvement in policy formation.

Note 11. Brady, Klark and Davis (1995) have developed a similar argument by integrating cognitive dissonance theory into public choice analysis of competition among pressure groups. Cognitive dissonance phenomenon may be used by activist groups in order to generate collective fears. Contrary to Kuran and Sunstein (1999), these authors do not analyze collective belief formation processes and their effects on public policy.

Note 12. One can refer to Kahneman and Tversky (1974). For an overview of different bias and heuristics in risk perception, one can refer to Sunstein (1998). Indeed, Noll and Krier (1990) discussed the contribution of cognitive psychologists on risk perception and analyzed their impact on irrational public policy (Viscusi \& Zeckhauser, 1990).

Note 13. Viscusi and Hamilton (1999) have also analyzed the issue of irrational risks policy (notably the superfund program established in 1980) and have shown the impact of risks perception bias and political factors on public policies. These authors have shown that these policies have reflected judgment errors because public decision makers were subject to citizen pressure who held erroneous judgments about risks.

Note 14. Superfund is the federal government's program to clean up the nation's uncontrolled hazardous waste sites

Note 15. A study of Allen (1987) comparing the ranking of environmental problems by U.S. citizens and EPA experts, showed different evaluation by these two actors. The more important risk for the public is that of toxic waste sites whereas EPA experts do not consider it dangerous. For Viscusi (1998), this erroneous perception of risks is attributable to the wide media coverage related to the "Love Canal" story.

Note 16. Simon (1982) was the first scholar who developed the concept of limited rationality.

Note 17. Kuran and Sunstein (1999) extend the analysis of Slovic (2000) related to the social amplification of risks. Although Slovic is aware of the importance of interdependence of individuals in risk perception, he does not explain social mechanisms leading to such biased perception. For Kuran and Sunstein (1999), it is reputational and informational cascades mechanisms throughout.

Note 18. As far as the political entrepreneur is concerned, we refer to the definition of Simmons et al., (2011) who develop a model of political entrepreneurship. Combining the Sutter (2002)'s definition who argues that entrepreneur " discover innovative ways to coordinate individual action for successful collective action" as well as the Boettke (1993)' s definition which states that the entrepreneur is a human actor " who possesses the propensity to pursue goals effectively, once ends and means are clearly identified, but also possesses the alertness to identify which ends are to be sough and what means are available", they define political entrepreneurship as " alertness to unnoticed opportunities to achieve desire political outcomes". Therefore, in the Kuran and Sunstein's story, activists may be defined as political entrepreneur.

Note 19. It may explain, for example, consumption behaviour in order to increase individuals' statute.

Note 20. This argument has been developed by Kuran (1991) to explain the emergence of revolutions and it focus particularly on the impact of internal and external costs associated with the opposition to the incumbent regime.

Note 21. Hung and Plott (2001) have demonstrated the existence reputation cascades through laboratory experiments.

Note 22. Such an idea seems validated by Morris (2001) who has shown that reputation effects lead to a loss of information for which the social value is high.

Note 23. Bonardi (2005) focus particularly on the impact of collective beliefs on firm's reaction. He suggests that firms may themselves adopt these strategies of political entrepreneurship to fight against collective beliefs when they endanger their profits or market shares.

Note 24. Inspired by the work of Kuran and Sunstein (1999), Lemennicier (2002) analyzes the interaction between informational and reputational mechanism, and their effects on risk regulation. He formalizes reputational 
cascades phenomenon among expert community and gives an explanation of the tobacco advertising ban. Also, Bonardi (2005) cites page (1999) who argues that the antitrust decisions against Microsoft cannot be explained by the lobbying activities of its competitors such as Netscape but, instead, by a "general opinion" conveyed by experts in the economic field. The process of reputation and information cascades helps explain this result. Jaeck (2011) also applies Kuran and Sunstein's framework to explain the differences of climate change regulations between the US and the EU. Also, Jaeck and Bougi (2010) has developed a theoretical model of political business cycles based on the assumption of cascades effects to deal with regulation cycles in the field of environmental policy.

Note 25. Such information related to the indeterminate characteristic is not transmitted through the label, the latter referring only to the good's credence characteristic, notably throughout the carbon printing. On the contrary, this information is related the product's environmental impact, namely its ability to contribute to the GHGs emission reduction. This information may emanate from different external sources such as green public campaign from the good's corporation, climate change campaign from the government, environmentalist expert discourse in the media etc...

Note 26. Let us note that Welsh and Kuhling (2009) have provided empirical evidences to the effect of reference groups on pro-environmental consumption. Indeed, they argue reference groups are important when the mode of consumer choice is imitation and social comparison. In this respect, cascades theory offers a challenging explanation of the sources of such imitative behaviours.

Note 27. Hung and Plot (2001) provided evidences of such reputation cascades through laboratory experiments.

Note 28. In the field of carbon labeling market, identifying empirical evidences of such corporate political strategies is interesting avenue for further research.

\section{Appendix}

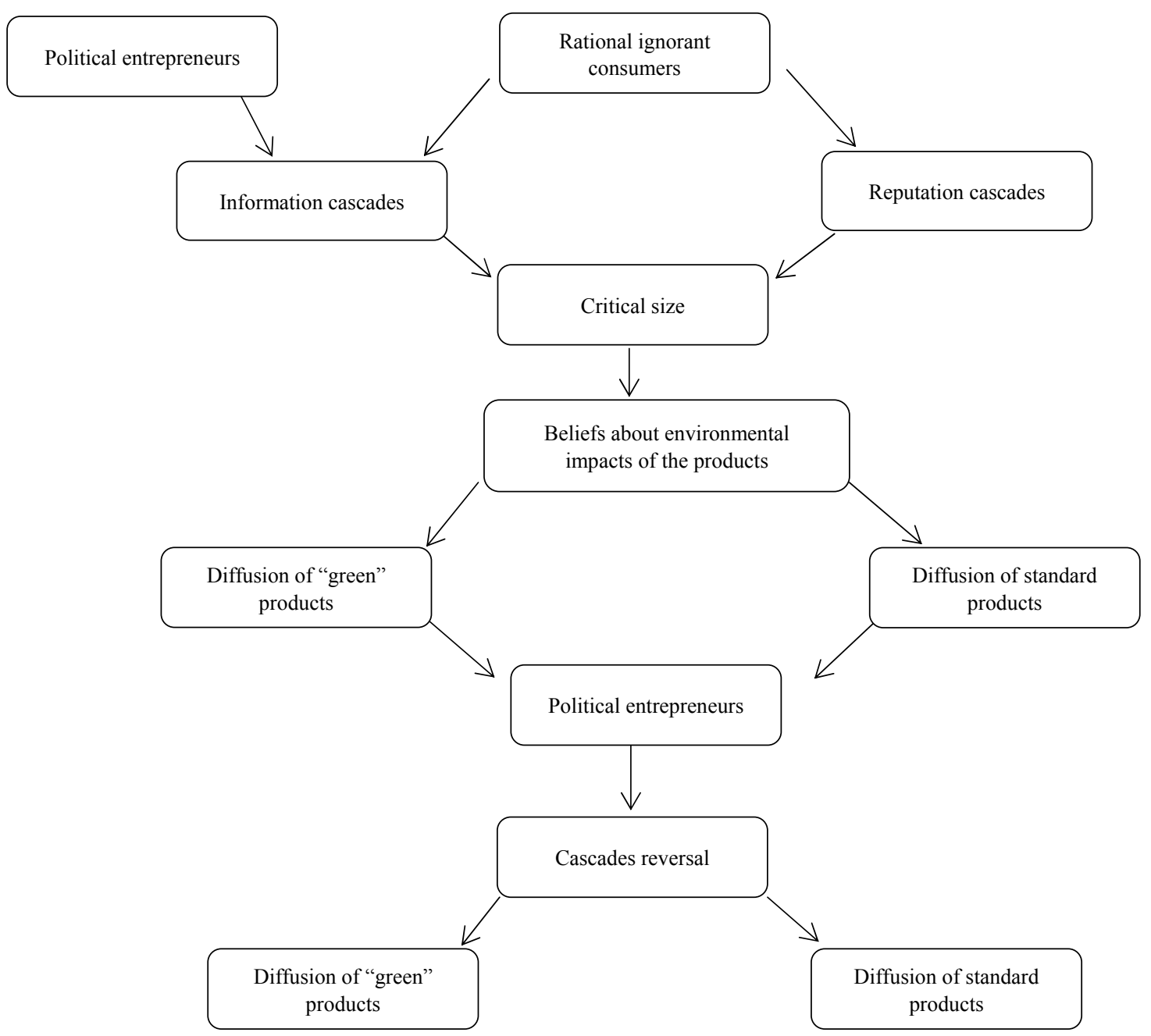

Figure 1. The random selection process 